\title{
PENGARUH REVOLUSI INDUSTRI 4.0 TERHADAP ONLINE SERVICE TERMINAL PETIKEMAS KOJA JAKARTA
}

\author{
Irena Relani ${ }^{1}$, Eko Nur Hidayat ${ }^{2}$ \\ ${ }^{1}$ Alumnus Politeknik Bumi Akpelni \\ ${ }^{2}$ Program Studi Teknika Politeknik Bumi Akpelni \\ Jl. Pawiyatan Luhur II/17 Bendan Dhuwur Semarang \\ e-mail : irenarelani2129@gmail.com
}

\begin{abstract}
Abstrak
Tujuan dari penelitian ini adalah untuk mengetahui dan menjelaskan tentang dampak Revolusi Industri 4.0 terhadap Online Service Terminal Petikemas Koja Jakarta dari sistem pembayaran, pelayanan yang ada di prosedur dan realisasinya di lapangan. Dalam penyusunan karya tulis ini, Penulis menggunakan beberapa metode atau cara dalam pengumpulan data, yaitu: Metode observasi, Metode Wawancara, dan Metode Kepustakaan. Dari pembahasan diperoleh bahwa pengaruh revolusi industry 4.0 sudah terasa di beberapa sistem pelayanan seperti E-ticket \& KIOSK walaupun masih dilakukan dengan semi otomatis, belum ada aplikasi online service secara real time terintegrasi. Hal ini membuat custumer masih harus datang memberikan data secara fisik, karena belum bisa diakses dimana saja dan kapan saja.
\end{abstract}

Kata kunci : real time, terintegrasi, pelayanan

\section{PENDAHULUAN}

Revolusi industri 4.0 atau dikenal juga dengan fourth industrial revolusi (4IR) merupakan era industrial keempat sejak revolusi industri pertama pada abad ke-18. Era 4IR ditandai dengan perpaduan teknologi yang mengaburkan batas antara bidang, digital dan biologis, atau secara kolektif disebut sebagai system siber-fisik (cyber-physical system/CPS). Revolusi industri 4.0 mengubah tatanan hampir setiap industri disetiap negara termasuk Indonesia, besarnya jangkauan perubahan ini menandai transformasi seluruh sistem produksi, manajemen, dan pemerintahan.

Efek implementasi era industry 4.0 diantaranya kegiatan industri mulai menggunakan sistem untuk mempercepat produktifitas kinerja layanan perusahaan, karena dalam kegiatan pelayanan harus menggunakan waktu seminimal mungkin untuk membuat konsumen selalu di layani dengan baik. perusahaan dapat menjadi pilihan utama sebagai jasa pelayanan dan di era saat ini terjadi revolusi indutri 4.0 yang seluruhnya dirubah pola pikir maupun kinerja industri dunia.

Terminal Petikemas Koja Jakarta termasuk salah satu industri yang terdampak harus mengikuti revolusi industri dengan memberikan pelayanan yang mengedepankan kecepatan dan miminimalkan waktu untuk membuat pelanggan puas terhadap pelayanan TPK Koja Jakarta sehinga meningkatkan loyalitas pelanggan untuk tetap menggunakan jasa TPK Koja sesuai dengan misinya menjadi terminal Container kelas dunia dengan memberikan pelayanan prima.

\section{METODE}

Dalam penelitian ini, metode yang digunakan adalah metode diskriptif yaitu mendeskripsikan atau memberi gambaran terhadap objek yang diteliti melalui data atau sampel yang telah terkumpul sebagaimana adanya tanpa melakukan analisis dan membuat kesimpulan yang berlaku untuk umum 


\section{LANDASAN TEORI}

Menurut Savitri (2019: 1 \& 65), revolusi industri 4.0 adalah era industri keempat sejak revolusi industri pertama pada abad ke-18. Era revolusi industri 4.0 ditandai dengan perpaduan teknologi yang mengaburkan batas antara bidang fisik, digital dan biologis, atau secara kolektif disebut sebagai sistem siber-fisik (cyber-physical system/CPS). Perkembangan dunia yang seperti itu akan mengubah tatanan hampir setiap industri, sistem produksi, manajemen, hingga sumber daya manusia, era ini setiap perusahaan bersiap menghadapi revolusi industri 4.0 untuk bisa berbenah agar tidak tenggelam oleh zaman. Menurut Forkomsi FEB UGM (2019:19), revolusi industri 4.0 adalah kecepatan perubahan yang dialami oleh organisasi dan individu karena inovasi teknologi yang muncul menciptakan cara untuk mengembangkan, bertukar, dan mendistribusikan nilai dan seluruh masyarakat. Revolusi industri 4.0 memberikan ruang untuk setiap manusia untuk berfikir kreatif dan inovatif untuk mengembangkan era revolusi yang mengharuskan berfikir cepat tepat dan mudah. Menurut Tjandrawinata (2016: 39), revolusi industri keempat dibangun di atas revolusi industri ketiga, yang juga dikenal sebagai revolusi digital, yang ditandai oleh proliferasi komputer dan otomatisasi pencatatan di semua bidang. Otomatisasi di semua bidang dan konektivitas adalah tanda- tanda yang nyata dari revolusi Industri keempat. Salah satu petanda unik dan khusus dari revolusi industri keempat adalah terjadinya aplikasi artificial intelligence (AI). revolusi industri ke 4 menyempurnakan revolusi ke 3 dengan terjadinya berbagai otomatisasi pencatatan disemua bidang. Menurut Schawab (2017), menjelaskan revolusi industri 4.0 telah mengubah hidup dan kerja manusia secara fundamental. Dari pengertian diatas penulis menyimpulkan sebuah perubahan yang terjadi keseluruhan dari dasar atau mendasar dari pola hidup manusia.

Dari pendapat para ahli diatas penulis menyimpulkan bahwa revolusi industri 4.0 adalah proses perubahan dari mulai pola pikir hingga perilaku manusia satau suatu perusahaan untuk mengimbangi suatu zaman dan menjadi lebih kreatif karena adanya digital menjadi suatu kebutuhan di era revolusi 4.0.

Menurut Loina (2001:38),
pelayanan adalah suatu proses keseluruhan dari pembentukan citra perusahaan, baik melalui media berita, membentuk budaya perusahaan secara internal, maupun melakukan komunikasi tentang pandangan perusahaan kepada para pemimpin pemerintahan serta publik lainnya yang berkepentingan. Suatu pembentukan citra untuk suatu daya tarik bagi konsumen atau pelanggan perusahaan atau organisasi. Menurut Freddy dalam Amstrong (2018: 143), pelayanan atau service adalah setiap kegiatan atau manfaat yang dapat diberikan oleh suatu pihak kepada pihak lainnya yang pada dasarnya tidak berwujud dan tidak pula berakibat pada pemilikan sesuatu. Terjadinya manfaat namun anya sekedar tindakan bukan memberikan suatu barang untuk dimiliki. Menurut Moenir dalam Yudha (2011: 17), pelayanan adalah kegiatan yang dilakukan oleh seseorang atau sekelompok orang dengan landasan faktor material melalui sistem, prosedur dan metode tertentu dalam rangka usaha memenuhi kepentingan orang lain sesuai dengan haknya. Untuk memenuhi suatu usaha harus adanya pelayanan atau service yang baik bagi customer atau pelanggan. Menurut Groonros (1990:27) dalam Ratminto dan Atik (2005:2), pelayanan adalah suatu aktivitas atau serangkaian aktivitas yang bersifat tidak kasat mata (tidak dapat diraba) yang terjadi sebagai akibat adanya interaksi antara konsumen dengan karyawan atau hal-hal lain yang di sediakan oleh 
perusahaan pemberi pelayanan yang dimaksudkan untuk memecahkan permasalahan konsumen atau pelanggan. suatu komunikasi untuk melihat interaksi yang baik dalam pelayanan di perusahaan membentuk citra perusahaan. Menurut Sora (2015), online adalah istilah saat kita sedang terhubung dengan internet atau dunia maya, baik itu terhubung dengan akun media sosial kita, email dan berbagai jenis akun lainnya yang kita pakai atau gunakan lewat internet. Menurut Studinew (2016), online merupakan istilah yang sering kita gunakanketika terhubung dengan internet atau dunia maya. Terhubungnya internet itu walaupun hanya terhubung dengan media sosial kita hingga email dan segala macam jenis akun yang kita miliki untuk dapat menggunakan internet. Saat ini banyak sekali cara yang dapat di gunakan untuk dapat online internet salah satunya dengan menggunakan smartphone yang memiliki kota atau layana internet kita bias langung masuk ke jaringan internet. Online dapat di lakukan kapanpun dan dimanapun karena online internet tidak memiliki batasan waktu dan usia hingga semua orang dapat mengakses internet dengan nyaman. Online di katakana bagi pengguna internet yang berhasil masuk ke dalamn jaringan internet tanpa mengalami suatu kendala.

Dari pendapat para ahli diatas penulis menyimpulkan bahwasannya pelayanan dan online digabung menjadi pelayanan online atau online service adalah pelayanan yang berusaha mmeberikan suatu layanan di perusahaan dengan yang terbaik dan menggunakan teknologi secara online melalui web.site resmi perusahaan.

Menurut Zebua (2018:20), pelayanan customer pada pemasaran barang dan jasa adalah lebih dilihat sebagai hasil dari kegiatan distribusi dan logistik, dimana pelayanan customer meliputi aktivitas untuk memberikan kegunaan waktu dan tempat termasuk pelayanan pra transaksi, saat transaksi, pasca transaksi. Kegiatan tersebut harus cepat dan tanggap, kegiatan pra transaksi harus sebaik mungkin sehingga customer memberikan respons yang positif dan menunjukan loyalitas yang tinggi. Setiap pelayanan customer harus sangat baik dan sempurna terkadang apa yang diberikan harus segera terlaksana dikarenakan setiap customer adalah raja diharuskan pelayanan harus prima. Menurut Ikatan Banker Indonesia (2014: 64-65) customer service adalah kata customer service berasal dari dua kata yaitu " customer" yang berarti pelanggan, dan "service" yang mengandung arti pelayanan. Waworuntu (1997) customer serviceadalah melayani nasabah, dimana untuk bidang bisnis secara umum diartikan sebagai pelayanan pelanggan. Customer service merupakan suatu bagian dari unit organisasi yang berada di front office yang berfungsi sebagai sumber informasi dan perantara bagi bank dan nasabah yang ingin mendapatkan jasajasa pelayanan maupun produk produk bank. Sesuai fungsinya customer service diharapkan dapat melakukan "one stop service", artinya nasabah cukup menghubungi bagian customer service saja dalam berhubungan dengan bank. Menurut Gea dan Wulandari(2006:344-345), pelayanan prima adalah pada umunya bersifat intangibles, tidak dapat dilihat dan diraba sehingga penggunanya hanya bisa merasakan melalui pengalaman langsung. Pelayanan mencakup juga halhal yang tangibles, yang bisa dilihat dan diraba, berupa dimensi fisik dari pelayanan itu sendiri. Usaha-usaha pelayanan jasa seperti perbankan, asuransi, perhotelan, pariwisata, rumah sakit, lembaga pendidikan, serta usaha jasa lainya, memiliki kedua dimensi tersebut yang telihat dan tidak terlihat.

Dari pendapat para ahli diatas penulis penyimpulkan customer service dan pelayanan prima harus sangat 
berkaitan dikarenakan suatu pelayanan seharusnya harus dilakukan dengan secara prima atau sempurna agar pelanggan tetap setia pada jasa perusahaan berikan atau layanan yang di berikan.

Menurut Lasse (2014:100), auto gate system adalah inovasi dalam pelayanan gate in dan gate out petikemas di pelabuhan dengan menerapkan sistim teknologi di terminal. Teknologi ini penting untuk efesiensi pelayanan keluar masuk truck container. Dengan cara menerapkan pertukaran data elektronik antara shipping line, importer, eksportir, perusahaan, trucking, PPJK, FA, bea dan cukai, TPK Koja dan bank yang di kemas dalam sebuah sistem yang dinamakan auto gate system.

Dilihat dari kata auto

gate system, terdapat 3 suku

kata antara lain:

1) Auto (otomatis) dalam kamus besar bahasa Indonesia Online, arti kata "otomatis" yaitu otomatis/ oto-matis/ secara otomatis, dengan bekerja sendiri, dengan sendirinya.

2) Gate (gerbang /gapura) dalam kamus besar bahasa Indonesia online, arti kata "gerbang / gapura" yaitu gapura ga-pu-ra/ pintu besar untuk masuk pekarangan rumah (jalan, taman, dan sebagainya), pintu gerbang.

3) System (sistem) dalam kamus besar bahasa Indonesia online, arti kata "sistem"e yaitu sistem /sis-tem/ perangkat unsur yang secara teratur saling berkaitan sehingga membentuk suatu totalitas.

Auto gate system menggunakan teknologi terbaru yang memungkinkan pengemudi truk dapat melewati gate terminal peti kemas, tanpa penundaan dan pemeriksaan secara manual

Menurut Donna dan Sisilia (2013:20-21), elektronik tiket (e-ticket) adalah dokumen perjalanan elektronik yang tidak perlu dicetak resmi di kertas . pelanggan bisa mencetaknya sendiri dirumah dengan kertas berkas yang bisa digunakan bolak balik. Pada konter chek in di bandara atau stasiun dan atau tempat lainya. kita hanya menunjukan tanda pengenal KTP jika di Bandara atau Paspor.

Dari pendapat para ahli diatas penulis menyimpulkan bahwa setiap $e$ ticket atau auto gate itu seluruhnya menggunakan sistem secara electronic dan seluruh data bisa di akses tanpa adanya banyak data yang masuk secara fisik.

Menurut Lasse (2014:179), delivery order adalah surat perintah pengeluaran peti kemas atau surat asli perintah pengeluaran, dan dengan surat perintah ini bisa melakukan pembayaran dan lalu menerima job order. Untuk memberikan ijin keluar masuk container ke dalam wilayah terminal ataupun pelabuhan. Menurut Ayu (2010: 1), delivery order adalah sebuah dokumen yang berperan sebagai surat perintah penyerahan barang yang telah dipesan dengan kesepakatan bersama antara penjual dan pembeli yang ditujukan kepada bagian gudang sebuah perusahaan.

Menurut Baraniah (2014:118) transhipment cargo adalah perpindahan komoditas ke alat angkut lain, selain singgahnya alat angkut. Perpindahan komoditas tersebut dapat terjadi secara utuh perpindahanya ke laut angkut lain atau dapat menambah / mengurangi jumlah (volume) dalam suatu wadah / kontainer. Dari suatu perpindahan barang ke kapal sebelumnya menjadikan terjadinya transipmen dari kapal kecil ke kapal besar untuk menuju tujuan barang.

Menurut Erick dan Reza (2019:7), aplikasi real time adalah program aplikasi yang memiliki rentang waktu yang dirasakan pengguna secara langsung atau terjadi saat itu juga. Rentan waktu secara langsung yaitu suatu pembayaran yang sangat cepat 
tetapi sudah tersistem secara online dengan satu waktu. Menurut Joko (2015:30), sistem otomatis adalah setiap bisnis online yang sukses menggunakan sistem otomatis di dalamnya, sistem otomatis untuk menghasilkan prospek baru, sistem otomatis untuk melaksanakan follow up tanpa henti, sistem otomatis untuk melayani pemesanan, pengiriman, dan sebagainya. Jika perlu untuk mengotomatiskan pemantauan kegiatan reseller, memantau trafficnya, hasil penjualannya dan membagikan komisinya, semua harus otomatis, semua sistem bisnis bisa anda jalankan semua dengan otomatis. Menurut Rama dan Jones (2008:37), penerjemah( Edward Tanujaya) sistem manual adalah mengatasi masalah akuntasi dengan pembukan laporan dan pembukuan secara manual. Sistem manual adalah sistem yang secara manual tidak otomatis terjadi harus menggunakan tenaga manusia.

Dari pendapat para ahli diatas penulis menyimpulkan bahwa setiap proses real time hanya menggunakan satu waktu dan otomatis menggunakan sistem otomatis dan manual menggunakan tenaga manusia.

\section{METODE}

Dalam penelitian ini menggunakan metode descriptive, yaitu dengan membuat deskripsi, gambaran, atau lukisan secara sistematis, faktual dan akurat mengenai fakta-fakta, sifat-sifat serta hubungan antarfenomena yang diteliti, dalam ha ini di terminal Petikemas Koja.

\section{HASIL DAN PEMBAHASAN}

Salah satu indikator kualitas sebuah terminal petikemas itu bisa dilihat dari kecepatan pelayanannya, karenan di era revolusi industri 4.0 seluruhnya seharusnya sudah real time tetapi tidak untuk Terminal Petikemas Koja.

Pelayanan Pendaftaran Id Card Pengguna Jasa masih dilakukan di customer service, belum dapat dilakukan secara on line dari luar TPK Kojasedangkan perubahan password sudah dapat dilakukan secara mandiri melalui WEB \& MOBILE dengan mengakses link ebilling.tpkkoja.co.id/rebilling/

Pelayanan Penggunaan aplikasi KIOSK juga masih terbatas di lingkungan Terminal Petikemas Koja. Transaksi via KIOSK berlaku untuk dokumen import/export standard online, selain itu dilakukan transaksi melalui loket billing.

Pengurusan pembayaran tarif jasa untuk mengeluarkan petikemas import dan eksport dari Terminal Petikemas Koja Jakarta walaupun sudah online tetapi masih melalui Customer Service dengan membawa dokumen untuk mendapatkan e-ticket. Proses pembayaran belum real time dilihat dari proses pelayanan nya sangat memakan waktu yang lama berikut perbandingan data relevan yang sesuai prosedur dan data sesuai dilapangan : 
Tabel 1 Prosedur pelayanan dan waktu

\begin{tabular}{|c|c|c|c|}
\hline $\mathrm{NO}$ & Jasa pelayanan & Target & Realisasi \\
\hline 1. & $\begin{array}{l}\text { Pelayanan Jasa Bongkar Muat } \\
\text { Petikemas Ekspor, Impor : Pedoman } \\
\text { Mutu \& Kebijakan Mutu } \\
\text { Sistem Manajemen Mutu KSO } \\
\text { TPK Koja 2017. ISO 9001:2015 }\end{array}$ & 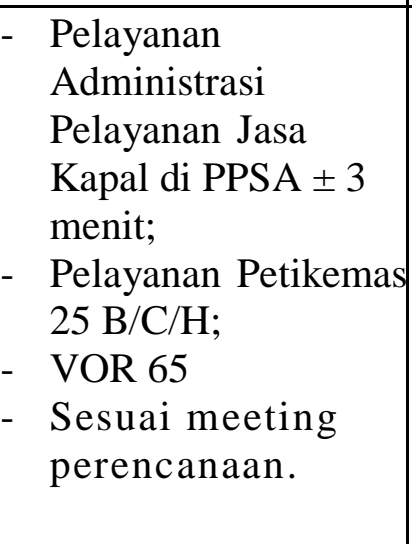 & $\begin{array}{ll}\text { - } & \text { Pelayanan } \\
\text { - } & \text { Administrasi } \\
& \text { Pelayanan Jasa } \\
& \text { Kapal di PPSA } 6 \\
& \text { menit; } \\
\text { - } & \text { Pelayanan } \\
& \text { Petikemas } \\
& 25 \mathrm{~B} / \mathrm{C} / \mathrm{H} ; \\
\text { - } & \text { VOR 65 } \\
\text { - } & \text { Ses uai meeting } \\
& \text { perencanaan. }\end{array}$ \\
\hline 2 & $\begin{array}{l}\text { Pelayanan Dokumen } \\
\text { Pedoman Mutu \& Kebijakan } \\
\text { Mutu } \\
\text { Sistem Manajemen Mutu KSO TPK } \\
\text { Koja 2017. ISO 9001:2015 }\end{array}$ & - & - 6 menit \\
\hline 3 & $\begin{array}{l}\text { Pelayanan Petikemas Transhipment } \\
\text { Pedoman Mutu \& Kebijakan } \\
\text { Mutu } \\
\text { Sistem Manajemen Mutu KSO TPK } \\
\text { Koja 2017. ISO 9001:2015 }\end{array}$ & 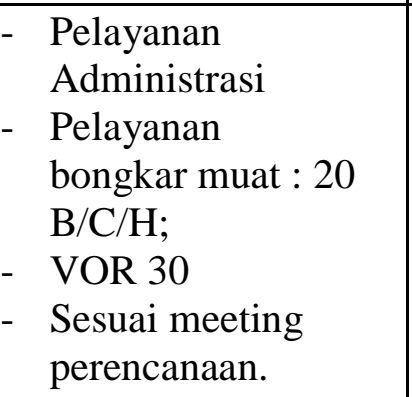 & $\begin{array}{ll}\text { - } & \text { Pelayanan } \\
& \text { Administrasi } \\
\text { - } & \text { Pelayanan bongkar } \\
& \text { muat : } 20 \mathrm{~B} / \mathrm{C} / \mathrm{H} ; \\
\text { - } & \text { VOR } 30 \\
\text { - } & \text { Sesuai meeting } \\
& \text { perencanaan. }\end{array}$ \\
\hline 4 & $\begin{array}{l}\text { Pelayanan Petikemas Refer } \\
\text { Pedoman Mutu \& Kebijakan } \\
\text { Mutu } \\
\text { Sistem Manajemen Mutu KSO TPK } \\
\text { Koja 2017. ISO 9001:2015 }\end{array}$ & 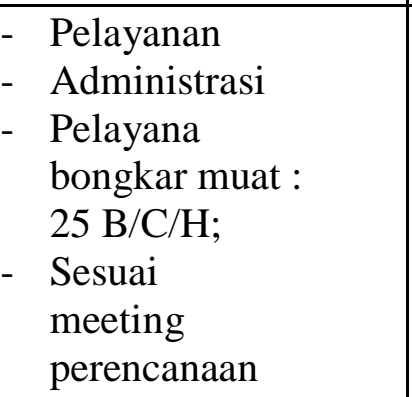 & 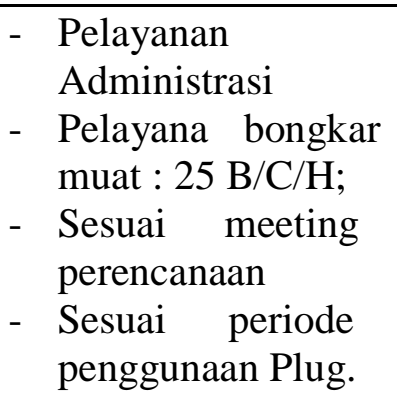 \\
\hline 5 & $\begin{array}{l}\text { Pelayanan Petikemas Karantina } \\
\text { Pedoman Mutu \& Kebijakan } \\
\text { Mutu } \\
\text { Sistem Manajemen Mutu KSO TPK } \\
\text { Koja 2017. ISO 9001:2015 }\end{array}$ & $\begin{array}{ll}- & \text { Pelayanan } \\
& \text { Administrasi } \\
\text { - } & \text { Pelayanan } \\
\text { - } & \text { Petikemas } 25 \mathrm{~B} / \mathrm{C} / \mathrm{H} ; \\
\text { - } & \text { Sesuai meeting } \\
& \text { perencanaan. }\end{array}$ & $\begin{array}{ll}\text { - } & \text { Pelayanan } \\
& \text { Administrasi } \\
\text { - } & \text { Pelayanan } \\
& \text { Petikemas } 25 \\
\text { B/C/H; } \\
\text { - } \\
\text { Sesuai meeting }\end{array}$ \\
\hline
\end{tabular}




\begin{tabular}{|l|l|l|l|}
\hline 6 & Pelayanan Auto Gate & - & Pelayanan Gate In < \\
& Pedoman Mutu \& Kebijakan & 3 menit & $\begin{array}{l}\text { Pelayanan Gate In 4 } \\
\text { menit }\end{array}$ \\
& Mutu & Pelayanan Gate Out & Pelayanan Gate Out \\
& Sistem Manajemen Mutu KSO TPK & < 3 menit \\
& Koja 2017. ISO 9001:2015 & TRT 70'AVE & \\
\hline
\end{tabular}

Sumber : Data hasil observasi lapangan TPK Koja

Dari hasil pengamatan, system yang sudah online walaupun secara local tetapi belum terintegrasi dengan perbankan (proses pembayaran tarif jasa impor dan ekspor) karena dibagian tersebut sistemnya masih manual dan adanya antrian, walaupun sudah menggunakan bank transaksinya tetapi harus menunjukan bukti (invoice) karena jika untuk data impor dan ekspor akan diragukan saat electronic capture yang nantinya akan terjadi container bodong tanpa keterangan jelas (sudah dibayar atau belum) tidak jelas keterangannya, akan merugikan pihak TPK Koja. Proses transaksi belum real time dan tahapannya membuat waktu lebih lama dari target pelayanan dan antrian banyak dibagian costumer service/billing, dan pengaruh revolusi industri di bagian billing jelas hanya menerapkan semi revolusi indutri 4.0. Hal ini dapat diatasi dengan mengembangkan system terintegrasi dengan perbankan, agar tidak harus menunjukan bukti pembayaran atau nota pembayaran. TPK Koja sangat bisa maju untuk terintegerasi dengan membuat aplikasi yang ada di smartphone dan membuat customer saat transaksi tidak harus menggunakan invoice atau performa dan datang kekantor TPK Koja untuk transaksi ,tetapi sudah tertera disistem bahwa setiap customer dibuatkan virtual account, sehingga transaksi bisa kapan saja dan dimana saja, melayani dengan cepat untuk pelanggan. Solusi dan trobosan baru untuk Terminal Petikemas Koja Jakarta. Dan ini sangat berpengaruh untuk mencapai revolusi industri 4.0 bagai tpk Koja kedepan jika menerapkan sistem tersebut.

Delivery order adalah surat penerbitan pihak shipping atau forwader kepada shipper sebagai tanda bukti pengambilan peti kemas kosong dan atau tanda bukti pengiriman barang dari gudang shipper ke UTPK (Unit Tempat Penumpukan Peti Kemas) atau warehouse. Pelayanan delivery $d i$ $T P K$ Koj a yang masih menggunakan sistem semi otomatis. Proses verifikasi dokumen, proses pembayaran, memberikan Invoice dan E-ticket masih manual di front office. Proses ini akan membutuhkan waktu.

Tabel 2 Perbandingan waktu pelayanan

\begin{tabular}{|l|l|l|}
\hline Pelayanan & Target & Realisasi \\
\hline Pelayanan Auto Gate & - Pelayanan Gate In $<3$ & - Pelayanan Gate In \\
Pedoman Mutu \& Kebijakan & menit & -4 menit \\
Mutu & - Pelayanan Gate Out $<3$ & - Pelayanan Gate Out \\
Sistem Manajemen Mutu KSO & menit & 4 menit \\
TPK Koja 2017. ISO 9001:2015 & - TRT 70'AVE & - TRT 70'AVE \\
& & \\
\hline
\end{tabular}

Sumber : data hasil observasi lapangan di TPK Koja 
Dari perbandingan waktu pelayanan, terlihat bahwa kinerja TPK Koja sudah mendekati pencapaian target waktu pelayanan. Untuk itu dapat dilakukan upaya-upaya untuk meningkatkan kecepatan waktu pelayanan, antara lain dengan mengembangkan system E-ticket dengan terintegrasi agar system delivery order cepat dan mudah. Dengan menggembangkan daftarkan di aplikasi smartphone dengan banyaknya pilihan layanan yang hanya dalam satu genggaman semua akan bisa diatasi tanpa pelanggan datang untuk mengurus dokumen dan lain sebagainya.

Transhipment adalah salah satu pelayanan Terminal Petikemas Koja Jakarta untuk pemindahan muatan kapal dari feeder ship ke mothership atau kapal yang lebih besar.

Belum ada system transhipment yang otomatis baik transshipment KojaKoja maupun JICT-Koja, sehingga masih memerlukan banyak dokumen dan sdm di dalam handle transshipment. Untuk itu, TK Koja dapat membuat sistem otomatis untuk handle transhipment. Sistem N-gen sebenarnya sudah ada untuk transhipmen tetapi belum lengkap hanya untuk pemuatan saja dan mengupdate dan mengolah/crate pemuatan dan pembongkaran. Seharusnya sistem N-gen harus lebih di kembangkan kembali secara otomatis agar tidak menggunakan email lagi sehingga tidak hanya untuk operasi perencanaan membuat atau mengolah pemuatan dan pembongkatan container saja, tetapi untuk update data secara otomatis.

\section{KESIMPULAN}

Revolusi industri 4.0 sangat berpengaruh terhadap pelayanan di Terminal Petikemas Koja, yaitu dengan menerapkan pelayanan mengarah ke pemanfaatan teknologi informasi. Walaupun belum dapat menerapkan secara full otomatisasi, yaitu beberapa pelayanan masih tetap menggunakan manual dan ada beberapa system belum terintegrasi tetapi pengaruh revolusi industry 4.0 sudah sangat diasakan manfaatnya dari sisi kemudahan dan kecepatan waktu pelayanan walaupun belum maksimal.

\section{DAFTAR PUSTAKA}

Abdullah Baraniah Muchtar. 2014. Penanganan Memahami Importasi Hewan Produknya. Jakarta: Penerbit Swadaya

Asmara Usi dan B Budiningsih . 2007. Pemikiran Kreatif Pemasaran. Yogyakarta : Penerbit Amara Book.

Atosokhi Gea Antonius dan Panca Yuni Wulandari Antonina.2006. Relasi dengan Dunia (Alam, Iptek dan Kerja): Jakarta : PT Elex Media Komputindo.

Bahriani Khaer Intan. 2015. Revolusi Industri. Makalah Ini Tidak di Publikasikan.

Donna Widjajanto dan Sisilia Kinanti. 2013. Green Traveling Jakarta_: PT Gramedia Pustaka Utama.

FEB UGM Forkomsi . 2019. Revolusi Industri 4.0 . Jawa Barat : CV Jejak , Anggota IKAPI.

Indonesia Ikatan Bankir. 2014. Mengelola Kualitas Layanan Perbankan. Jakarta : Gramedia Pustaka Utama.

Ismail.2018. Manajemen Perbankan. Jakarta: Prenadamedia Group (Devisi Kencana).

Kurniawan Erick dan Faisal M Reza. 2019. Membangun Aplikasi Realtime dengan ASP.NET Core Signal IR. Jakarta: Erick Kurniawan. Lasse,D.A..2014. Manajemen Kepelabuhanan. Jakarta: PT Raja Grafindo Persada. Mahmudi Ali .2008. Myob Accouting dan Premier. Jakarta: Grasindo.

Moenir, A, S. 2010. Manajemen Pelayanan Umum Di Indonesia. Yogyakarta: Bumi Aksara 
Nusantara Agung,2001, Dampak korupsi Terhadap Ekonomi. Skripsi Ini Tidak Di Publikasikan.

Rangkuti, Freddy. 2017. Customer Care Excellence. Jakarta: Gramedia Pustaka Utama.

Rezky Al idrus. 2016. Pelaksanaan Penerimaan Dan Penyerahan Peti Kemas Pada PT Pelabuhan Indonesia IV Makasar. Skripsi Ini Tidak di Publikasikan.

Rochim Nur.2017. Strategi Dan Sistem Pemasaran Container Pada Container Maritime Activities (CMS CGM) Cabang Semarang. Karya Tulis Ini Tidak di Publikasikan.

Savitri Astrid.2019. Revolusi Industri 4.0, Mengubah Tantangan Menjadi Peluang Di Era Dirupsi 4.0. Yogyakarta: Penerbit Ganesis.

Sasono Herman Budi.2012. Managemen Pelabuhan dan Realisasi Ekspor Impor. Yogyakarta : CV Andi Offset. Setianto Buddy.2016. Saham-Saham Industri Infrastructure, Toll dan Transportation di BEI Laporan Keuangan Akhir Tahun. Jakarta: BSK Capital.

Siahaan Wilmar Jonris , 2016, “ Kualitas Pelayanan Kapal Dan Kecepatan Bongkar Muat Kapal
Terhadap Produktivitas Dermaga Terminal Petikemas Pelabuhan Makassar" : Skripsi Tidak di Publikasikan.

Susilo Joko.2015. Sistem Mesin Otomoatis : Bisnis Internet Paling Direkomendasikan: Formula 3 Langkah Memulai dan Membangun Bisnis Melalui Internet. Jakarta : Forbis Corp.

Sudiarto I Nyoman,2018. Daya Tarik Wisata Jogging track_ : Jakarta : Nilacakra

Tambunan Toman Sony dan Tambunan Wilson R.G..2019. Hukum Bisnis. Jakarta: Prenadamedia Group (Devisi kencana)

Tim Prima Pena. 2014. Kamus Besar Bahasa Indonesia. Jakarta: Gitamedia Press.

V. Rama Dasaratha -L. Jones Frederick penerjemah (Edward Tanujaya). 2008. Sistem Informasi Akuntansi. Jakarta : Salemba Empat

Yudi Setianto Anton dan Jehani L, Budiman Niko, Jehadun,N Agnes. 2008. Paduan Lengkap Mengurus Perijinan dan Dokumen. Jakarta: Niaga Swadaya Praninta Offset.

Zebua, Manahati .2018. Pemasaran Pariwisata. Yogyakarta: Deepublis 